OPEN ACCESS

Edited by:

Raul Antonio Sperotto,

Centro Universitário Univates, Brazi

Reviewed by:

Gwen-Aelle Grelet,

Landcare Research, New Zealand

Marc Libault,

University of Oklahoma, USA

Marcela Claudia Pagano,

Brazil

*Correspondence:

Xiurong Wang

xrwang@scau.edu.cn

Jiandong Sheng

sjd_2004@126.com

Specialty section:

This article was submitted to

Plant Nutrition,

a section of the journa

Frontiers in Plant Science

Received: 24 August 2016 Accepted: 01 December 2016 Published: 16 December 2016

Citation:

Wang G, Sheng L, Zhao D, Sheng J, Wang $X$ and Liao H (2016) Allocation of Nitrogen and Carbon Is Regulated

by Nodulation and Mycorrhizal Networks in Soybean/Maize Intercropping System.

Front. Plant Sci. 7:1901. doi: 10.3389/fpls.2016.01901

\section{Allocation of Nitrogen and Carbon Is Regulated by Nodulation and Mycorrhizal Networks in Soybean/Maize Intercropping System}

\author{
Guihua Wang ${ }^{1}$, Lichao Sheng', Dan Zhao ${ }^{2}$, Jiandong Sheng ${ }^{2 *}$, Xiurong Wang ${ }^{1 *}$ and \\ Hong $\mathrm{LiaO}^{3}$
}

${ }^{1}$ State Key Laboratory for Conservation and Utilization of Subtropical Agro-bioresources, Root Biology Center, South China Agricultural University, Guangzhou, China, ${ }^{2}$ Xinjiang Key Laboratory of Soil and Plant Ecological Processes, College of Grassland and Environmental Sciences, Xinjiang Agricultural University, Urumai, China, ${ }^{3}$ Root Biology Center, Fujian Agriculture and Forestry University, Fuzhou, China

Soybean/maize intercropping has remarkable advantages in increasing crop yield and nitrogen $(\mathrm{N})$ efficiency. However, little is known about the contributions of rhizobia or arbuscular mycorrhizal fungi (AMF) to yield increases and $\mathrm{N}$ acquisition in the intercropping system. Plus, the mechanisms controlling carbon $(\mathrm{C})$ and $\mathrm{N}$ allocation in intercropping systems remain unsettled. In the present study, a greenhouse experiment combined with ${ }^{15} \mathrm{~N}$ and ${ }^{13} \mathrm{C}$ labeling was conducted using various inoculation and nutrient treatments. The results showed that co-inoculation with AMF and rhizobia dramatically increased biomass and $\mathrm{N}$ content of soybean and maize, and moderate application of $\mathrm{N}$ and phosphorus largely amplified the effect of co-inoculation. Maize had a competitive advantage over soybean only under co-inoculation and moderate nutrient availability conditions, indicating that the effects of AMF and rhizobia in intercropping systems are closely related to nutrient status. Results from ${ }^{15} \mathrm{~N}$ labeling showed that the amount of $N$ transferred from soybean to maize in co-inoculations was $54 \%$ higher than that with AMF inoculation alone, with this increased $\mathrm{N}$ transfer partly resulting from symbiotic $\mathrm{N}$ fixation. The results from ${ }^{13} \mathrm{C}$ labeling showed that ${ }^{13} \mathrm{C}$ content increased in maize shoots and decreased in soybean roots with AMF inoculation compared to uninoculated controls. Yet, with co-inoculation, ${ }^{13} \mathrm{C}$ content increased in soybean. These results indicate that photosynthate assimilation is stimulated by AM symbiosis in maize and rhizobial symbiosis in soybean, but AMF inoculation leads to soybean investing more carbon than maize into common mycorrhizal networks (CMNs). Overall, the results herein demonstrate that the growth advantage of maize when intercropped with soybean is due to acquisition of $\mathrm{N}$ by maize via $\mathrm{CMNs}$ while this crop contributes less $\mathrm{C}$ into $\mathrm{CMN}$ s than soybean under co-inoculation conditions.

\footnotetext{
Keywords: arbuscular mycorrhizal inoculation, carbon allocation, common mycorrhizal network, ${ }^{15} \mathrm{~N}$ labeling, nitrogen transfer, rhizobium inoculation, soybean/maize intercropping, ${ }^{13} \mathrm{C}$ labeling
}

Abbreviations: AMF, Arbuscular mycorrhizal fungi; CMN, common mycorrhizal network; IM, intercropped maize; IS, intercropped soybean; LN, low N; LP, low P; MM, monoculture maize; MN, medium N; MP, medium P; MS, monoculture soybean; N, nitrogen; $\mathrm{P}$, phosphorus. 


\section{INTRODUCTION}

Intercropping is an essential element of agricultural sustainability, and widely practiced in tropical, subtropical, and temperate areas (Maffei and Mucciarelli, 2003; Brooker et al., 2015). One common intercropping scheme is to pair a cereal crop with a legume that can supply $\mathrm{N}$ through biological $\mathrm{N}_{2}$ fixation. Yield advantages of intercropping legumes with non- $\mathrm{N}_{2}$ fixing crops have been found in many intercropping systems, including ryegrass-subclover (Ledgard et al., 1985), rice-peanut (Shen and Chu, 2004), wheat-faba bean (Xiao et al., 2004), Millet-cowpea (Laberge et al., 2011), rapeseed-faba bean (Jamont et al., 2013), and maize-soybean (Tang et al., 2005; Meng et al., 2015). Despite the prevalence of such cropping systems, the mechanisms underlying yield advantages of intercropping compared with monocropping systems have not been fully explored.

It has been reported that intercropping advantages can be explained by above-ground plant-plant interaction effects on light absorption, maintenance of optimal temperatures and space, or below-ground interactions, including root-root interactions, and interactions between roots and beneficial soil microbes (Brooker et al., 2015; Li et al., 2016; Xue et al., 2016). Rootroot interactions may benefit intercropped plants in several ways. In the soybean/maize intercropping system, maize yields are greater when intercropped with soybean genotypes with shallow roots than with deep root architectures (Tang et al., 2005). Intercropped plants may also benefit from root exudates of neighboring plants. In the fababean/maize intercropping system, the release of root exudates by fababean promotes acidification of the rhizosphere and enhances $P$ mobilization and acquisition in maize (Li et al., 2007), while root exudates from maize stimulate flavonoid synthesis and nitrogen fixation in fababean (Li et al., 2016).

Interactions between roots and beneficial soil microbes also play very important roles in increasing intercropping advantages. Beneficial soil microbes, such as AMF, can promote the mineralization and mobilization of nutrients, and more importantly provide pathways for transfer of nutrients through CMNs between intercropped crop species (Newman et al., 1994; Xiao et al., 2004; He et al., 2005; Walder et al., 2012). The CMNs can also facilitate transfer of carbon, water, defense signals and allelochemicals between cocultivated crops (Meding and Zasoski, 2008; Mikkelsen et al., 2008; Simard et al., 2012; Walder et al., 2012; Deslippe et al., 2016). Another beneficial soil microbe, Rhizobium, is able to interact with roots of legumes to form $\mathrm{N}$-fixing nodules, which increases the supply of $\mathrm{N}$ in intercropping systems. It has been demonstrated that intercropped crops may benefit from symbiotic associations with both rhizobia and AMF. Nitrogen fixed by legume plants can be transferred to non-legumes via root contact or CMNs in many intercropping systems (Xiao et al., 2004; Sierra and Nygren, 2006; Laberge et al., 2011; Meng et al., 2015). However, net N transfer from legumes to non-legumes through CMNs has been sparsely documented.

Plants transfer as much as $4-16 \%$ of photosynthetically fixed carbon (C) to AM and rhizobial symbionts in order to maintain an extensive hyphal network and nodule growth (Wright et al., 1998; Kaschuk et al., 2009). There is evidence the benefits of $\mathrm{CMN}$, as well as the $\mathrm{C}$ costs of AMF and rhizobia, vary among cocultivated plants, and depend on the AMF and plant species involved, soil nutrient supply and growth conditions (Kaschuk et al., 2009; Walder et al., 2012; Fellbaum et al., 2014). Meanwhile, carbon sink strengths of rhizobial and AM symbioses can also stimulate photosynthetic carbon assimilation (Kaschuk et al., 2009). However, until now, how the partitioning of photosynthate among intercropped legumes and non-legumes is regulated by beneficial soil microbes has been largely unexplored. In addition, mechanisms controlling carbon allocation among intercropped crops connected by a CMN are unsettled.

Soybean (Glycine max L.) and maize (Zea mays L.) are important food crops. Soybean/maize intercropping is one of the most common agricultural cultivation systems in China. Intercropping soybean can improve maize growth in the field (Tang et al., 2005). However, exactly how soybean promotes maize growth and the potential roles of AM and rhizobial symbiosis remain unclear. Therefore, we hypothesized that the growth advantage of maize when intercropped with soybean is partly due to allocation of carbon and nitrogen regulated by nodulation and mycorrhizal networks. In the present study, soybean and maize grown in an experimental intercropping system were inoculated with AMF and/or rhizobia in order to explore the contributions of AMF and rhizobia in this intercropping system, and to quantify nitrogen transfer and carbon allocation via ${ }^{15} \mathrm{~N}$ and ${ }^{13} \mathrm{C}$ isotope labeling.

\section{MATERIALS AND METHODS}

\section{Experimental Materials}

The two host plants used were the soybean variety HN89 and the maize variety Tiannuo. The AM fungal partner was Rhizophagus irregularis (DAOM 197198; accession no. AUPC00000000; Tisserant et al., 2013; Wang et al., 2016), and the rhizobial isolate was belonging to Bradyrhizobium elkanii strain BXYD3.

\section{Experimental Design}

One greenhouse experiment and one growth chamber labeling experiment were conducted. The greenhouse experiment was carried out to check soybean growth performance in response to the varying $\mathrm{N}$ and $\mathrm{P}$ levels, and rhizobium and $\mathrm{AM}$ inoculation treatments, which included four $\mathrm{N}$ and $\mathrm{P}$ treatments (LN and P, LNLP, $265 \mu \mathrm{M} \mathrm{N}$ and $25 \mu \mathrm{M} \mathrm{P}$; LN and medium P, LNMP, $265 \mu \mathrm{M} \mathrm{N}$ and $250 \mu \mathrm{M} \mathrm{P}$; MN and LP, MNLP, $2650 \mu \mathrm{M} \mathrm{N}$ and $25 \mu \mathrm{M} \mathrm{P} ; \mathrm{MN}$ and P MNMP, $2650 \mu \mathrm{M} \mathrm{N}$ and $250 \mu \mathrm{M}$ $\mathrm{P}$ ), two culture modes (monoculture and intercropping) and three combinations of AM fungal and rhizobium inoculation treatments, including an uninoculated control $(-\mathrm{A}-\mathrm{R}), \mathrm{AM}$ fungal inoculation $(+A-R)$, and inoculation of both the AMF and rhizobium $(+A+R)$. There were four replicates of each treatment. The growth chamber labeling experiment had one $\mathrm{N}$ and $\mathrm{P}$ treatment $(530 \mu \mathrm{M} \mathrm{N}$ and $50 \mu \mathrm{M} \mathrm{P})$ with two cropping systems (monoculture and intercropping) and three combinations of AM fungal and rhizobium inoculation $(-\mathrm{A}-\mathrm{R}$, 
$+\mathrm{A}-\mathrm{R}$ and $+\mathrm{A}+\mathrm{R}$ ) in order to explore $\mathrm{N}$ transfer and $\mathrm{C}$ allocation in CMNs. $\mathrm{N}$ and $\mathrm{P}$ concentrations were increased compared to LNLP levels in greenhouse experiment, but had not been increased to those at MNMP levels since the plants in MNMP were too large to handle for ${ }^{13} \mathrm{C}$ labeling. There were six replicates of each treatment. Three were used for ${ }^{15} \mathrm{~N}$ and ${ }^{13} \mathrm{C}$ labeling, and the other three were used as controls to examine natural ${ }^{15} \mathrm{~N}$ and ${ }^{13} \mathrm{C}$ abundances, and adjust for the ${ }^{15} \mathrm{~N}$ and ${ }^{13} \mathrm{C}$ abundance of plant samples from the background contribution.

\section{Growth Conditions}

A two-compartment growth system was employed for both the greenhouse experiment and the growth chamber labeling experiment (Supplementary Figure S1). Soybean and maize plants were grown side by side in the two-compartment system constructed out of perspex boxes $(13 \mathrm{~cm} \times 12 \mathrm{~cm} \times 12 \mathrm{~cm})$. The two compartments were evenly separated by a perforated perspex divider $(0.5 \mathrm{~cm}$ wide) to form a $0.5 \mathrm{~cm}$ air gap in order to prevent ion diffusion between compartments. Every side of the divider was enclosed by a $30 \mu \mathrm{m}$ nylon mesh that allowed only fungal hyphal connection while preventing root contacts. Every compartment was filled with $1 \mathrm{~kg}$ of growth substrate consisting of a $4: 1 \mathrm{mix}$ of sand and soil that was autoclaved in two $1 \mathrm{~h} 121^{\circ} \mathrm{C}$ treatments in order to inhibit microbial contamination. The growth substrate had a $\mathrm{pH}$ of 5.0 when mixed with water, along with $1.2 \mathrm{mg} \mathrm{kg}^{-1}$ of available $\mathrm{P}$ as determined by the Bray II method, and $47.2 \mathrm{mg} \mathrm{kg}^{-1}$ of available $\mathrm{N}$ as determined by the alkali-hydrolyzed diffusion method.

In the greenhouse experiment, plants were grown under natural light in the intensity range of 500-1800 $\mu \mathrm{mol} \mathrm{m} \mathrm{m}^{-2} \mathrm{~s}^{-1}$. Diurnal air temperatures ranged consistently between 20 and $28^{\circ} \mathrm{C}$. Prior to planting, $10 \%$ dry inoculum was incorporated into the growth substrate. The inoculum consisted of colonized millet root fragments and a soil:sand mix containing the spores and extraradical hyphae of $R$. irregularis. The uninoculated control also incorporated the $10 \%$ soil:sand mix from millet grown without mycorrhizal inoculation. Soybean seedlings were inoculated with $2 \mathrm{~mL}$ rhizobium solution 1 week after germination (Wang et al., 2011). Plants were watered with soybean nutrient solution (Zhang et al., 2015) containing different $\mathrm{N}$ and $\mathrm{P}$ concentrations every week throughout the growth period.

In the growth chamber labeling experiment, plants were grown in a walk-in growth chamber with a $16 \mathrm{~h}$ photoperiod, a $24^{\circ} \mathrm{C} / 22^{\circ} \mathrm{C}$ day/night temperature cycle, and a light intensity of $455 \mu \mathrm{mol} \mathrm{m}^{-2} \mathrm{~s}^{-1}$. After germination, seedlings were inoculated by adding 500 spores of $R$. irregularis into the soil close to the roots. After 1 week, soybean seedlings were inoculated with $2 \mathrm{~mL}$ of rhizobium solution (Wang et al., 2011). Plants were watered every week with soybean nutrient solution containing $50 \mu \mathrm{M} \mathrm{P}$ and $530 \mu \mathrm{M}$ N.

\section{${ }^{15} \mathrm{~N}$ and ${ }^{13} \mathrm{C}$ Labeling}

In the growth chamber labeling experiment, ${ }^{15} \mathrm{~N}$ labeling was conducted according to Xiao et al. (2004) with some modifications. Six weeks after planting, soybean plants were labeled through petiole injection with $\left({ }^{15} \mathrm{NH}_{4}\right)_{2} \mathrm{SO}_{4}$ enriched with $99 \%{ }^{15} \mathrm{~N}$. Ten microliter of $88 \mathrm{mM}\left({ }^{15} \mathrm{NH}_{4}\right)_{2} \mathrm{SO}_{4}$ solution was injected through a $25 \mu \mathrm{L}$ syringe each day for 9 days in succession, and thereby supplying every soybean plant with a total of $0.22 \mathrm{mg}{ }^{15} \mathrm{~N}$.

${ }^{13} \mathrm{C}$ labeling was conducted according to $\mathrm{Lu}$ et al. (2002a) with some modifications. Briefly, at the time of labeling, the surface of the perspex boxes was sealed with plastic film with a narrow slot for the shoot to ensure the isolation of the shoots from the roots, and to create a shoot-labeling box. The Perspex boxes were transferred to transparent labeling chambers $(50 \mathrm{~cm} \times 52 \mathrm{~cm} \times 50 \mathrm{~cm})$, which was also sealed to prevent ${ }^{13} \mathrm{CO}_{2}$ leakage. ${ }^{13} \mathrm{CO}_{2}$ gas inside the chamber was generated by adding lactic acid into vial of $\mathrm{Ba}^{13} \mathrm{CO}_{3}\left(98 \%{ }^{13} \mathrm{C}\right)$ with a syringe. The mean ${ }^{13} \mathrm{CO}_{2}$ concentrations were $400-450 \mu \mathrm{L} \mathrm{L}^{-1}$ in the chamber. Four fans were used to recirculate the air within the closed labeling chambers. Plants were labeled at midmorning for $6 \mathrm{~h}$, and then taken out from the chamber for 3 days before harvesting.

\section{Harvest}

After 50 days, plants in the greenhouse experiment were harvested. Shoots, roots, and nodules were separated for determining plant dry weight, plant $\mathrm{N}$ and $\mathrm{P}$ concentrations, nodule number, and nodule fresh weight. One fresh root subsample was weighed and then cleared with $10 \% \mathrm{KOH}$ solution and stained with 5\% ink-vinegar solution for assessing AM colonization (Wang et al., 2016). Nitrogen and P concentrations were measured using a San++ SKALAR continuous flow analyzer (Skalar, The Netherlands) after acid digestion.

In the growth chamber labeling experiment, plants were harvested 3 days after ${ }^{13} \mathrm{C}$ labeling, and the shoots, roots and nodules were separated. The roots were washed, weighed, and divided into two portions; one subsample was used for determination of AM colonization (Wang et al., 2016); and the rest of the samples were dried to determine ${ }^{15} \mathrm{~N}$ and ${ }^{13} \mathrm{C}$ concentrations, along with $\mathrm{N}, \mathrm{C}$, and $\mathrm{P}$ concentrations. The concentrations of ${ }^{15} \mathrm{~N}$ and ${ }^{13} \mathrm{C}$ in the shoots, roots, and nodules were determined using Delta $\mathrm{V}$ Advantage isotope ratio mass spectrometry (Thermo Finnigan, German). Total carbon was determined using a Euro EA3000 single elemental analyzer (Euro Vector, Italy).

\section{${ }^{15} \mathrm{~N}$ Transfer Calculations}

$\mathrm{N}$ transfer was calculated as follows (He et al., 2009; Meng et al., 2015):

$$
\begin{aligned}
& \text { Percentage } \mathrm{N} \text { transfer }\left(\% \mathrm{~N}_{\text {transfer }}\right) \text { : } \\
& \% \mathrm{~N}_{\text {transfer }}={ }^{15} \mathrm{~N}_{\text {content }} \text { maize } \times 100 /\left({ }^{15} \mathrm{~N}_{\text {content }} \text { maize }+\right. \\
& \left.{ }^{15} \mathrm{~N} \text { content } \text { soybean }\right)
\end{aligned}
$$

Where ${ }^{15} \mathrm{~N}$ content $=$ atom $\%{ }^{15} \mathrm{~N}$ excess $\times$ total $\mathrm{N}$; The atom $\%$ ${ }^{15} \mathrm{~N}$ excess was calculated by subtracting the natural abundance of ${ }^{15} \mathrm{~N}$ in unlabeled soybean or maize from the measured atom\% ${ }^{15} \mathrm{~N}$ of labeled soybean or maize. 
Amount of $\mathrm{N}$ transferred from soybean to maize $\left(\mathrm{N}_{\text {transferred }}\right.$, mg plant $\left.^{-1}\right)$ :

$$
\mathrm{N}_{\text {transferred }}=\% \mathrm{~N}_{\text {transfer }} \times \text { total } \mathrm{N}_{\text {soybean }}
$$

Percentage $\mathrm{N}$ in maize derived from transfer (\% NDFT):

$$
\% \mathrm{NDFT}=\mathrm{N}_{\text {transfer }} \times 100 / \text { total } \mathrm{N}_{\text {maize }}
$$

The percent $\mathrm{N}$ derived from the atmosphere fixed by soybean (\% Ndfa, Xiao et al., 2004):

$$
\begin{aligned}
& \% \mathrm{Ndfa}=\left(1-\text { atom } \%{ }^{15} \mathrm{~N} \text { excess } \text { mixed soybean } / \text { atom } \%\right. \\
&{ }^{15} \mathrm{~N} \text { excess } \\
&\text { mono maize }) \times 100
\end{aligned}
$$

where mono maize is the maize grown in monoculture. Mixed soybean is the soybean grown in soybean/maize intercropping.

\section{${ }^{13} \mathrm{C}$ Content Calculations}

The content of ${ }^{13} \mathrm{C}$ incorporated into different tissues (shoots, roots, or nodules) of soybean or maize was calculated based on the difference in atom $\%{ }^{13} \mathrm{C}$ excess of the labeled and non-labeled tissues as follows (Lu et al., 2002b):

$$
\begin{aligned}
{ }^{13} \mathrm{C}= & \left(\text { atom } \%{ }^{13} \mathrm{C} \text { excess labeled }- \text { atom } \%\right. \\
& \left.{ }^{13} \mathrm{C} \text { excess } s_{\text {non-labeled }}\right) \times \mathrm{TC} \times 100
\end{aligned}
$$

where TC indicates the total tissue $\mathrm{C}$ content.

\section{Statistical Analyses}

All of the data were analyzed to calculate mean and SE using Microsoft Excel 2007 (Microsoft Company, USA). SAS (SAS Institute Inc., Cary, NC, USA) was used for two-way (inoculation treatment and cropping system) or three-way (nutrient treatment, inoculation treatment, and cropping system) analysis of variance (ANOVA). Mean separation was conducted using the Duncan Multiple Range Test (DMRT) following twoor three-way ANOVA, and the least significant difference (LSD) for the two cropping systems or for two inoculation treatments.

\section{RESULTS}

\section{Plant Growth in the Greenhouse Experiment}

The results showed that soybean and maize growth was significantly affected by $\mathrm{N}$ and $\mathrm{P}$ availability $(P<0.0001$; Table 1 , Supplementary Table S1). Biomasses of monocropped soybean and maize in the moderate $\mathrm{N}$ and $\mathrm{P}$ (MNMP) treatment increased by $68-173$ and $311-502 \%$, respectively, and those IS and maize biomasses increased by 53-158 and 247-766\%, respectively, compared with their biomasses in the corresponding LN and P (LNLP) cultures (Table 1).

AM fungal and rhizobium inoculation produced great effects on soybean and maize growth. Inoculation with rhizobia and/or AMF dramatically increased biomass of soybean and maize $(P<0.0001$; Table 1, Supplementary Table S1). Compared to uninoculated controls, in LNLP, soybean biomass in monoculture and intercropping systems increased by 38 and $52 \%$, respectively, with only AMF inoculation, and by 55 and 66\%, respectively, with co-inoculation, while maize biomass increases were 81 and $37 \%$, respectively, with only AMF inoculation, and 81 and 33\%, respectively, with coinoculation. Moderate application of $\mathrm{N}$ and $\mathrm{P}$ amplified the effect of AM fungal and rhizobium inoculation, with monoculture and intercropped biomass increases compared to uninoculated controls of 124 and 156\%, respectively, for soybean inoculated

TABLE 1 | Biomasses of soybean and maize inoculated with AMF and rhizobia under different $\mathrm{N}$ and $\mathrm{P}$ conditions in a greenhouse experiment.

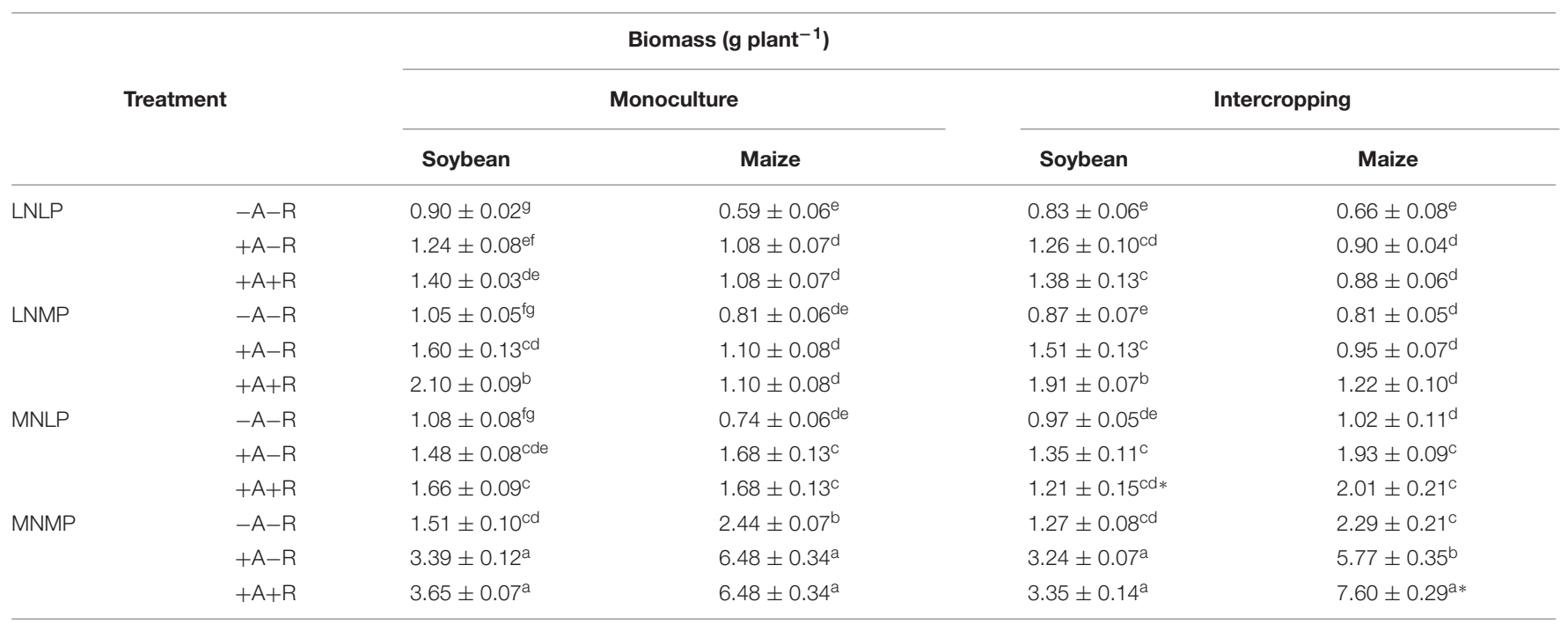

Data in the table are the mean of four replicates with standard error. Different letters indicate significant differences among nutrient treatments within a cropping system and crop species (Duncan's multiple range test, $P<0.05$ ). Asterisks indicate significant differences between monoculture and intercropped plants within a crop species and nutrient treatment (LSD test, $P<0.05)$. LNLP, low N and P; LNMP, low $N$ and moderate $P ; M N L P$, moderate $N$ and low P; MNMP, moderate N and $P$. 
with AMF alone, 141 and 164\%, respectively, for co-inoculated soybean, 165 and $152 \%$, respectively, for maize only inoculated with AMF, and 165 and 233\%, respectively, for co-inoculated maize.

Cropping system had a significant effect on soybean growth $(P<0.0001$; Table 1; Supplementary Table S1). Biomasses of all soybean plants in intercropping treatments were lower than in monoculture across nutrient levels and inoculation treatments. Under moderate $\mathrm{N}$ and low $\mathrm{P}$ (MNLP) conditions, IS biomass was $27 \%$ less than in monoculture. Conversely, all maize plants in monoculture and intercropping systems responded positively to increased nutrient and inoculation treatments (Table 1; Supplementary Table S1). Yet, the only effect of intercropping observed for maize was when the biomass of IM was 17\% higher than the biomass of monocultured maize in the MNMP and co-inoculation treatment.

In addition, total biomass of IM and soybean was also significantly affected by nutrient availability and inoculation treatments. Co-inoculation had positive effects on total biomass in both monoculture and intercropping systems, and moderate application of $\mathrm{N}$ and $\mathrm{P}$ amplified the effect of co-inoculation. Total biomass was obviously higher than those of sole maize and soybean in the MNMP and co-inoculation treatment $(P<0.0001$; Figure 1; Supplementary Table S1).

\section{Plant $\mathbf{N}$ and $\mathbf{P}$ Contents in the Greenhouse Experiment}

Nitrogen and $\mathrm{P}$ contents of all soybean and maize plants were significantly affected by $\mathrm{N}$ and $\mathrm{P}$ availability, along with $\mathrm{AM}$ fungal and rhizobium inoculation. This is consistent with the plant biomass results (Table 1). Moderate $\mathrm{N}$ and $\mathrm{P}$ application significantly enhanced $\mathrm{N}$ and $\mathrm{P}$ contents compared to low application rates regardless of inoculation treatment or cropping

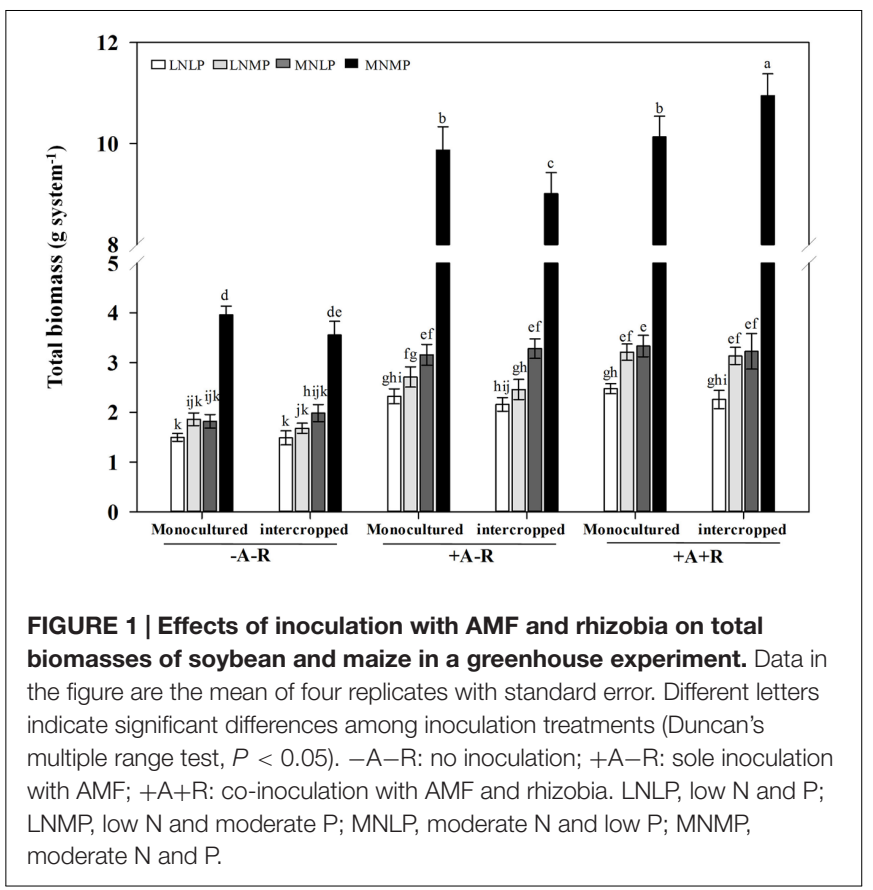

system $(P<0.0001$; Tables 2 and 3; Supplementary Table $\mathrm{S} 1)$. Both soybean and maize accumulated more $\mathrm{N}$ and $\mathrm{P}$ with MN and MP availability than those with LN and LP availability. Inoculations of soybean and maize with AMF and rhizobia significantly enhanced the contents of $\mathrm{N}$ and $\mathrm{P}$ in all cropping and nutrient treatments, except for the $\mathrm{N}$ and $\mathrm{P}$ contents of IM in the co-inoculation treatment reared in the LN treatment $(P<0.0001$; Tables 2 and 3; Supplementary Table $\mathrm{S} 1)$. With inoculation, the respective $\mathrm{N}$ contents of soybean and maize increased by $19-273$ and $22-160 \%$, and the respective $\mathrm{P}$

TABLE 2 | $\mathbf{N}$ contents of soybean and maize inoculated with AMF and rhizobia under different $\mathrm{N}$ and $\mathrm{P}$ conditions in a greenhouse experiment.

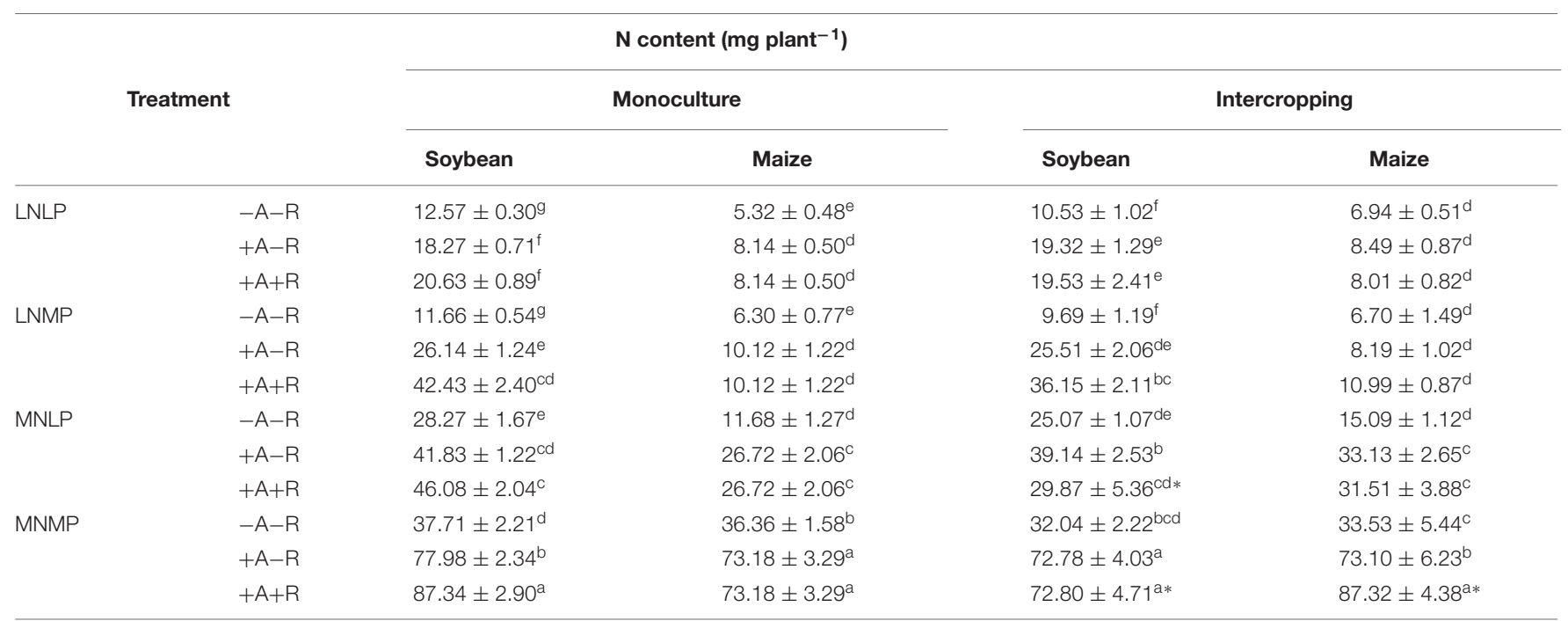

Data in the table are the mean of four replicates with standard error. Different letters indicate significant differences among nutrient treatments within a cropping system and crop species (Duncan's multiple range test, $P<0.05$ ). Asterisks indicate significant differences between monoculture and intercropped plants within a crop species and nutrient treatment (LSD test, $P<0.05)$. LNLP, low N and P; LNMP, low N and moderate P; MNLP, moderate N and low P; MNMP, moderate N and P. 
TABLE 3 | P contents of soybean and maize inoculated with AMF and rhizobia under different $\mathbf{N}$ and $\mathrm{P}$ conditions in a greenhouse experiment.

\begin{tabular}{|c|c|c|c|c|c|}
\hline \multicolumn{6}{|c|}{$P$ content (mg plant $\left.{ }^{-1}\right)$} \\
\hline \multicolumn{2}{|c|}{ Treatment } & \multicolumn{2}{|c|}{ Monoculture } & \multicolumn{2}{|c|}{ Intercropping } \\
\hline & & Soybean & Maize & Soybean & Maize \\
\hline \multirow[t]{3}{*}{ LNLP } & $-A-R$ & $0.53 \pm 0.05^{9}$ & $0.27 \pm 0.03^{d}$ & $0.54 \pm 0.03^{d}$ & $0.36 \pm 0.04^{e}$ \\
\hline & $+\mathrm{A}-\mathrm{R}$ & $0.95 \pm 0.04^{f}$ & $0.82 \pm 0.07^{\mathrm{c}}$ & $1.01 \pm 0.04^{\mathrm{C}}$ & $0.66 \pm 0.07^{\mathrm{de}}$ \\
\hline & $+\mathrm{A}+\mathrm{R}$ & $1.03 \pm 0.06^{f}$ & $0.82 \pm 0.07^{c}$ & $1.11 \pm 0.18^{\mathrm{c}}$ & $0.72 \pm 0.10^{\mathrm{de}}$ \\
\hline \multirow[t]{3}{*}{ LNMP } & $-A-R$ & $1.40 \pm 0.07^{e}$ & $0.86 \pm 0.03^{\mathrm{C}}$ & $1.08 \pm 0.08^{\mathrm{C} *}$ & $1.02 \pm 0.11^{d}$ \\
\hline & $+\mathrm{A}-\mathrm{R}$ & $2.78 \pm 0.03^{d}$ & $1.94 \pm 0.05^{b}$ & $2.88 \pm 0.21^{b}$ & $1.76 \pm 0.10^{\mathrm{cd}}$ \\
\hline & $+A+R$ & $3.69 \pm 0.16^{c}$ & $1.94 \pm 0.05^{b}$ & $3.19 \pm 0.17^{b}$ & $2.36 \pm 0.08^{\mathrm{C} *}$ \\
\hline \multirow[t]{3}{*}{ MNLP } & $-A-R$ & $0.58 \pm 0.11^{9}$ & $0.32 \pm 0.07^{d}$ & $0.47 \pm 0.07^{d}$ & $0.40 \pm 0.06^{\mathrm{e}}$ \\
\hline & $+\mathrm{A}-\mathrm{R}$ & $0.97 \pm 0.07^{f}$ & $0.89 \pm 0.11^{\mathrm{c}}$ & $0.91 \pm 0.04^{\mathrm{C}}$ & $1.19 \pm 0.16^{d}$ \\
\hline & $+A+R$ & $1.14 \pm 0.10^{\mathrm{ef}}$ & $0.89 \pm 0.11^{\mathrm{c}}$ & $0.67 \pm 0.12^{\mathrm{cd} *}$ & $0.98 \pm 0.13^{d}$ \\
\hline \multirow[t]{3}{*}{ MNMP } & $-A-R$ & $1.02 \pm 0.10^{f}$ & $1.80 \pm 0.28^{b}$ & $0.81 \pm 0.11^{c}$ & $1.27 \pm 0.29^{d}$ \\
\hline & $+\mathrm{A}-\mathrm{R}$ & $6.19 \pm 0.22^{b}$ & $6.20 \pm 0.27^{a}$ & $5.31 \pm 0.55^{a}$ & $7.12 \pm 0.65^{b}$ \\
\hline & $+A+R$ & $6.62 \pm 0.22^{a}$ & $6.20 \pm 0.27^{a}$ & $5.34 \pm 0.36^{a *}$ & $8.20 \pm 1.09^{a *}$ \\
\hline
\end{tabular}

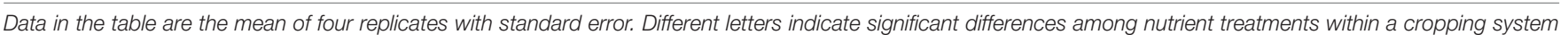

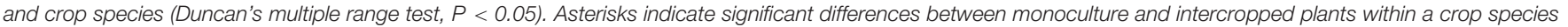
and nutrient treatment (LSD test, $P<0.05)$. LNLP, Iow N and P; LNMP, low N and moderate P; MNLP, moderate N and low P; MNMP, moderate N and P.

contents increased by $40-559$ and $74-544 \%$ over non-inoculated controls. Moderate $\mathrm{N}$ and $\mathrm{P}$ application once again amplified the differences among inoculation treatments.

The cropping system also significantly affected both $\mathrm{N}$ and $\mathrm{P}$ contents in soybean and maize $(P<0.0001$ for soybean; $P<0.05$ for maize; Tables 2 and 3; Supplementary Table S1). N and P contents of soybean plants had a decreasing trend, whereas those of maize plants showed an increasing trend from monoculture to intercropping. Furthermore, this difference in $\mathrm{N}$ and $\mathrm{P}$ contents between monocultured and IM/soybean tended to increase with increasing $\mathrm{N}$ and $\mathrm{P}$ availability, as well as, with $\mathrm{AM}$ fungal and rhizobium inoculation. Compared with the corresponding monocultured plants, the respective increases in the $\mathrm{N}$ and $\mathrm{P}$ contents of IM plants were 19 and $32 \%$, and the decreases in the respective $\mathrm{N}$ and $\mathrm{P}$ contents of IS were 17 and 19\% in the coinoculation treatment with MNMP availability (Tables 2 and 3). In addition, relative to monocultured maize and soybean, with co-inoculation, there was a $22 \%$ increase in the P content of IM in LN and moderate P (LNMP), along with 35 and 42\% decreases in $\mathrm{N}$ and $\mathrm{P}$ contents, respectively, of IS reared in MNLP.

\section{Mycorrhizal Colonization and Nodulation in the Greenhouse Experiment}

In the greenhouse experiment, all uninoculated plants were nonmycorrhizal (results not shown). All inoculated plants were well colonized by AMF, with AM colonization ranging between 74 and $87 \%$ in soybean, and between 76 and $86 \%$ in maize (Supplementary Figure S2). Even so, an effect of nutrient levels on AM colonization was observed $(P<0.05$; Supplementary Table S1). In soybean, AM colonization of monoculture plants in MNMP was $14.8 \%$ lower than in MNLP given only AM fungal inoculation.

$\mathrm{N}$ and $\mathrm{P}$ application also affected soybean nodulation $(P<0.0001$; Figure 2A; Supplementary Table S2). In comparison with the LNLP treatment, nodule fresh weights increased by 201 and $158 \%$ in LNMP, and by 70 and $48 \%$ in MNMP, whereas they decreased by 83 and $88 \%$ in MNLP for monocultured and IS, respectively. Nodule numbers also varied significantly among $\mathrm{N}$ and $\mathrm{P}$ treatments $(P<0.0001$; Figure 2B; Supplementary Table S2), with decreases of 88 and $246 \%$ observed in MNLP relative to the number of nodules observed on soybean growing in LNLP under monocropping and intercropping conditions, respectively. Between the two cropping systems, there were no significant differences observed in nodule fresh weight or nodule number, except that the number of nodules on monocropped soybean was $88 \%$ higher than on IS growing with MNLP availability (Figure 2B).

\section{$\mathrm{N}_{2}$ Fixation and Nitrogen Transfer in the Labeling Experiment}

To explore whether the growth differences observed between intercropped and the corresponding monocultured plants in co-inoculation treatments were due to $\mathrm{N}$ transfer through $\mathrm{CMN}$ after inoculation, the $\mathrm{N}$ transfer from soybean to maize was followed by ${ }^{15} \mathrm{~N}$ labeling in two compartment systems. As in the greenhouse experiment, inoculation with $\mathrm{AMF}$ and rhizobia significantly increased biomass and $\mathrm{N}$ content of soybean and maize irrespective of cropping system $(P<0.0001$; Supplementary Figure S3; Supplementary Table S3). No significant difference in AM colonization was observed among treatments, except that colonization was lower in monocultured soybean inoculated only with AMF than it was in co-inoculated and IS and maize (Supplementary Figure S4; Supplementary Table S3). Biomass and N contents of maize plants were obviously higher when grown together with a neighboring soybean in co-inoculation treatments $(P<0.01$; Supplementary Figure S3; Supplementary Table S3). In contrast, biomass and $\mathrm{N}$ content of IS showed the decreased trend 

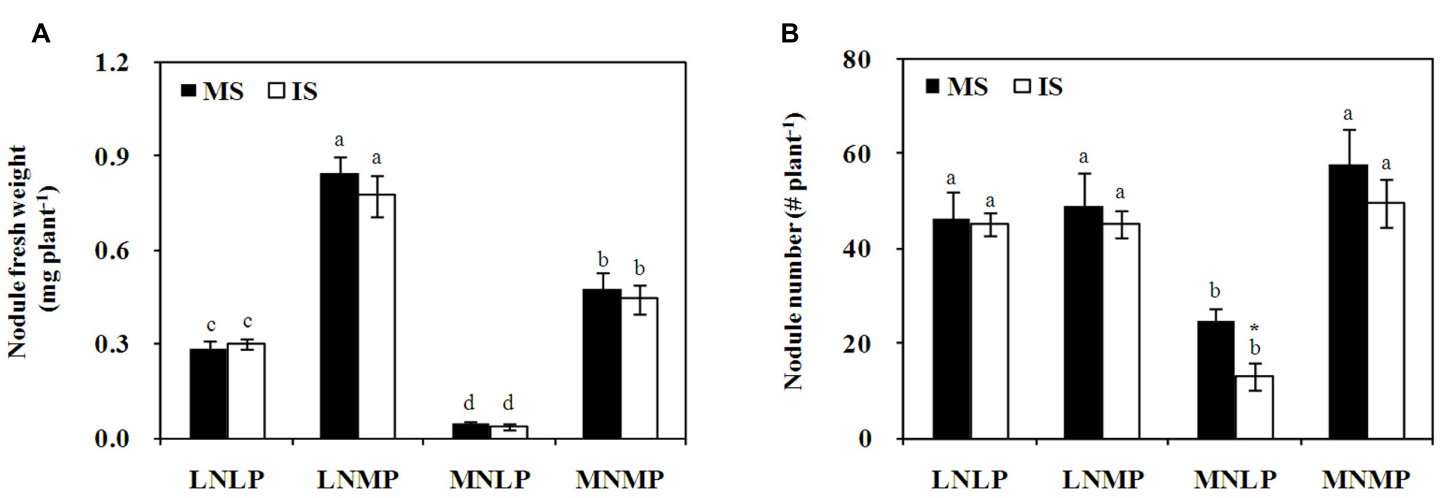

FIGURE 2 | Fresh weight (A) and numbers (B) of nodules collected from soybean reared under different $\mathrm{N}$ and $\mathrm{P}$ conditions in a greenhouse experiment. Data in the figure are the mean of four replicates with standard error. Different letters indicate significant differences among nutrient levels (Duncan's multiple range test, $P<0.05)$. Asterisks indicate significant differences between monoculture and intercropping within one nutrient level (LSD test, $P<0.05)$. (A): nodule fresh weight; (B): nodule number. MS, monoculture soybean; IS, intercropped soybean. LNLP, low N and P; LNMP, low N and moderate P; MNLP, moderate N and low P; MNMP, moderate $\mathrm{N}$ and $\mathrm{P}$.

compared with monocultured soybean (Supplementary Figure S3; Supplementary Table S3). As a consequence, soybean was, again, a weak competitor compared with maize in soybean/maize intercropping systems.

Biological nitrogen fixation was measured in the coinoculation treatment. Soybean displayed a high $\mathrm{N}$-fixing capacity, with more than $58 \%$ of its $\mathrm{N}$ being derived from the atmosphere (Table 4). This amounted to $13.4 \mathrm{mg} \mathrm{plant}^{-1}$ in the co-inoculation treatment. Petiole injection of ${ }^{15} \mathrm{~N}$ in the soybean donor was correlated with the appearance of the label in the maize receiver plants in the intercropping system. The ${ }^{15} \mathrm{~N}$ Petiole injection of soybean resulted in a higher $\mathrm{N}$ transfer from soybean to maize in both the AM fungal inoculation alone and the co-inoculation treatments. Although there was no significant difference in percentage of $\mathrm{N}$ transfer ( $\left.\% \mathrm{~N}_{\text {transfer }}\right)$ between the AM fungal inoculation alone and co-inoculation treatments, the amounts of $\mathrm{N}$ transferred from soybean to maize were significantly different, with 1.3 and $2.0 \mathrm{mg}$ plant $^{-1}$ observed, respectively (Table 4). Co-inoculation with AMF and rhizobia enhanced $\mathrm{N}$ transfer from soybean to maize, and the percentage $\mathrm{N}$ in maize derived from transfer (\% NDFT) increased from $11.1 \%$ with only AM fungal inoculation to $15.2 \%$ with coinoculation (Table 4).

\section{Carbon Allocation in the Labeling Experiment}

To evaluate the impacts of carbon allocation on the competitive abilities of maize and soybean in the intercropping system, pulse labeling of ${ }^{13} \mathrm{C}$ was performed with soybean and maize plants in a walk-in growth chamber. The results showed that ${ }^{13} \mathrm{C}$ content in monocultured and IS plants increased by 200 and $194 \%$ in shoots, and 130 and $113 \%$ in roots, respectively, with co-inoculation compared with uninoculated control plants $(P<0.0001$; Figure 3; Supplementary Table S3). However, nodule ${ }^{13} \mathrm{C}$ cost was similar in monocultured and IS, and accounted $7 \%$ of soybean root ${ }^{13} \mathrm{C}$ content, respectively, in co-inoculation treatment. Interestingly, the ${ }^{13} \mathrm{C}$ content of IS roots in the $\mathrm{AM}$
TABLE 4 | $\mathbf{N}$ transfer and proportion of $\mathbf{N}$ fixed by soybean as affected by inoculation in a growth chamber labeling experiment

\begin{tabular}{lcc}
\hline & +A-R & +A+R \\
\hline$\%$ Ndfa & & $58.4 \pm 6.8$ \\
Ndfa $\left(\right.$ mg plant $\left.^{-1}\right)$ & $13.4 \pm 3.4$ \\
$\%$ N transfer & $11.4 \pm 1.0^{\mathrm{a}}$ & $9.4 \pm 1.9^{\mathrm{a}}$ \\
$\mathrm{N}$ transferred $\left(\mathrm{mg} \mathrm{plant}^{-1}\right)$ & $1.3 \pm 0.1^{\mathrm{a}}$ & $2.0 \pm 0.2^{\mathrm{b}}$ \\
$\%$ NDFT & $11.1 \pm 0.8^{\mathrm{a}}$ & $15.2 \pm 1.2^{\mathrm{b}}$
\end{tabular}

Data in the table are the mean of three replicates with standard error. Different letters indicate significant differences between inoculation treatments (LSD test, $P<0.05)$. \% Ndfa: percent $N$ derived from the atmosphere fixed by soybean; \% $N_{\text {transfer: }}$ percentage $N$ transferred from soybean to maize; $N$ transferred: amount of $N$ transferred from soybean to maize; \% NDFT, percentage $N$ in maize derived from transfer.

fungal inoculation treatment exhibited a $34 \%$ decrease compared with uninoculated controls, as well as, 75 and $69 \%$ decreases in shoots and roots, respectively, compared to the co-inoculation treatment (Figure 3). In contrast, the ${ }^{13} \mathrm{C}$ content in IM shoots increased by $83 \%$ with AM fungal inoculation compared with uninoculated maize plants (Figure 3). These results indicate that photosynthate assimilation is stimulated by AM symbiosis in maize, and by rhizobial symbiosis in soybean, especially in the intercropping system.

\section{DISCUSSION}

In legume/cereal intercropping systems, legumes are generally weak competitors compared with cereals (Willey and Rao, 1980; Hauggaard-Nielsen and Jensen, 2001), which is often ascribed to differences in the root distributions of legumes and cereals, and the resulting differences in the ability of these crops to compete for soil N (Fan et al., 2006). In the maize/soybean intercropping system, the yield advantage of maize has been also reported (Tang et al., 2005; Meng et al., 2015). In the present study, we demonstrated that the high competitive ability of maize relative 


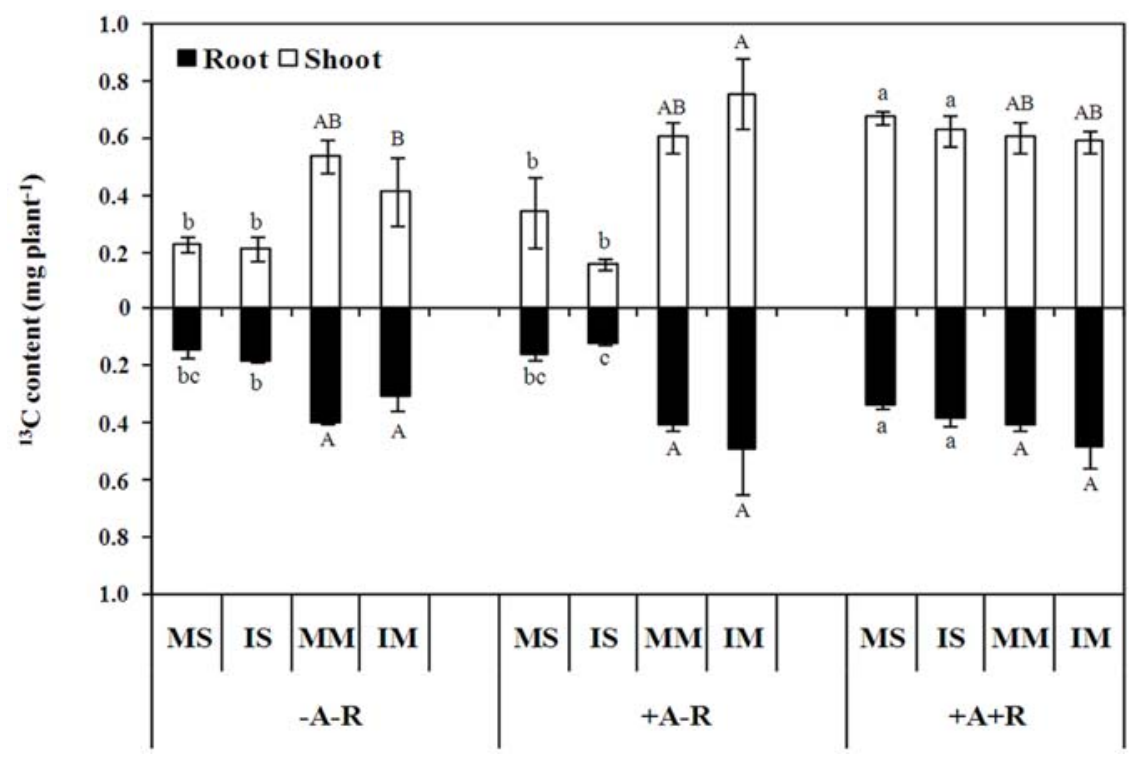

FIGURE $3 \mid{ }^{13} \mathrm{C}$ recovery from shoots and roots of soybean and maize after $6 \mathrm{~h}$ labeling under a ${ }^{13} \mathrm{CO}_{2}$-enriched atmosphere. Data in the figure are the mean of three replicates with standard error. Different letters indicate significant differences among inoculation treatments within a crop species (Duncan's multiple range test, $P<0.05)$. MS, monoculture soybean; IS, intercropped soybean. MM, monoculture maize; IM, intercropped maize. $-\mathrm{A}-\mathrm{R}$ : no inoculation; $+\mathrm{A}-\mathrm{R}$ : sole inoculation with AMF; + A+R: co-inoculation with AMF and rhizobia.

to soybean can be partly ascribed to the contribution of AMF and rhizobia. To our knowledge, this is the first report that the beneficial effects of intercropping on maize growth are due, at least in part, to allocation of carbon and nitrogen regulated by nodulation and mycorrhizal networks in the soybean/maize intercropping system.

Mycorrhizal colonization under high $\mathrm{P}$ conditions, and legume $\mathrm{N}$ fixation under high $\mathrm{N}$ conditions are often inhibited compared with these activities in $\mathrm{P}$ or $\mathrm{N}$ starved plants (Paynel et al., 2008; Breuillin et al., 2010; Balzergue et al., 2011; Wang et al., 2011). A previous study showed that co-inoculation with rhizobia and AMF significantly increases soybean growth in LP and/or LN conditions, but not with high $\mathrm{P}$ and high $\mathrm{N}$ nutrient availabilities (Wang et al., 2011). Therefore, in the present greenhouse experiments, medium N/P and LN/P treatments were employed to explore the effect of AMF and rhizobium inoculation on growth of IS and maize. The results showed that nodule fresh weight in MNMP was higher than in LNLP (Figure 2A). This indicates that an adequate nutrient supply is beneficial for nodule growth. In addition, both inoculation with AMF alone and co-inoculation with rhizobia promoted biomass, and increased the $\mathrm{N}$ and $\mathrm{P}$ contents of all soybean and maize plants compared with uninoculated controls regardless of nutrient status (Tables 1-3). Nevertheless, the largest effect of inoculation was found in MNMP relative to the other nutrient treatments, suggesting that the inoculation effect is dependent upon nutrient status. Another interesting phenomenon observed herein was that IM produced a yield advantage only in MNMP when co-inoculated with AMF and rhizobia (Tables 1-3). This implies that the contributions of AMF and rhizobia to crop advantages in intercropping are also closely related to nutrient status, which might in the end be ascribed to the regulation of $\mathrm{N}$ transfer and carbon allocation between maize and soybean.

It has been well reported that $\mathrm{N}$ can be transferred from legumes to cereals in intercropping systems by indirect or direct pathways (He et al., 2004, 2005, 2009; Xiao et al., 2004). Indirect pathways transfer $\mathrm{N}$ released from dead and decayed legume tissues, and from legume root exudates to the rhizosphere, where they are taken up from the soil solution by cereal roots or hyphae. Direct $\mathrm{N}$ transfer is mediated by CMN between coexisting legumes and cereals (He et al., 2004; Paynel et al., 2008). In the present work, petiole injection of ${ }^{15} \mathrm{~N}$ into soybean was used to detect direct $\mathrm{N}$ transfer from soybean to neighboring maize plants along an $\mathrm{N}$ concentration gradient via CMNs. Dividing cultures with a double nylon mesh and an air gap were designed to prevent the diffusion of nutrients, and allow passage of hyphae but not roots. The results showed that AMF inoculation alone resulted in a net $11.4 \%{ }^{15} \mathrm{~N}$ transfer, and co-inoculation of AMF and rhizobia led to a $54 \%$ increase in amount of ${ }^{15} \mathrm{~N}$ transferred from soybean to maize (Table 1). This considerable difference in the amount of $\mathrm{N}$ transferred between single and dual inoculation treatments indicates that mycorrhizae and rhizobia act together to enhance $\mathrm{N}$ fluxes from mycorrhizal soybean with nodules to mycorrhizal maize, and that increased $\mathrm{N}$ transfer partly results from symbiotic $\mathrm{N}$ fixation (Table 4). Therefore, increases in the biomass of maize are due to increases in $\mathrm{N}$ content resulting from intercropping with soybean and in the presence of both AMF and rhizobia.

The competitive advantage of maize when intercropped with soybean might also be due to changes in carbon allocation in these plants as affected by $\mathrm{AM}$ and rhizobium colonization. Rhizobial and AM symbioses typically consume $4-16 \%$ of plant 
photosynthetic carbon in order to maintain symbiont growth, activity and reserves, with co-colonization possibly leading to additive effects on C costs (Johnson et al., 2002; Kaschuk et al., 2009). Simultaneously, carbon sinks of rhizobial and AM symbioses can stimulate photosynthesis (Kaschuk et al., 2009). It is estimated that the rate of photosynthesis can increase by 28 and $14 \%$ in response to rhizobial and AM fungal inoculation, respectively, and by $51 \%$ with co-inoculation (Kaschuk et al., 2009). In the intercropping system, carbon can flow through CMNs (Walder et al., 2012). In the present study, IM with AMF alone contained more shoot ${ }^{13} \mathrm{C}$ than uninoculated maize, while soybean displayed the opposite effect (Figure 3). This indicates that AM fungal inoculation stimulates the capacity of maize to assimilate photosynthate, while IS invests more carbon into CMNs. On the other hand, with coinoculation, the ${ }^{13} \mathrm{C}$ content was highest for soybean in both shoots and roots compared with uninoculated soybeans or those inoculated with AMF alone, irrespective of cropping system, while no significant changes in maize ${ }^{13} \mathrm{C}$ content were found (Figure 3). Taken together, these results suggest that carbon fixation is stimulated by rhizobial symbiosis in soybean, and soybean plants, which are typically not C-limited, were then able to match increases in nutrient acquisition from roots with higher $\mathrm{N}$ content under co-inoculation conditions compared to instances of no symbiont inoculation or inoculation with AMF alone (Supplementary Figure S3). Furthermore, no differences in soybean biomass between uninoculated plants and those with AMF inoculation alone could be ascribed to higher $\mathrm{C}$ costs associated with AM fungal inoculation. Therefore, the loss of biomass in IS relative to monocultures might be attributable to increased $\mathrm{N}$ transfer to maize via CMNs in co-inoculation treatments. This still needs to be further clarified by quantitative analysis of carbon costs of extracted AMF hyphae in future studies.

Previous studies have shown that the $\mathrm{C}_{3}$ plant flax acquires more $\mathrm{N}$ and $\mathrm{P}$ provided by the $\mathrm{CMN}$ with little carbon costs, whereas the $\mathrm{C}_{4}$ plant sorghum invests more carbon with little $\mathrm{N}$ and $\mathrm{P}$ return (Walder et al., 2012). Therefore, the net benefit for flax is much greater than for sorghum in flax/sorghum mixed cultures. This is inconsistence with the present results, in which the $\mathrm{C}_{4}$ plant maize shows a higher competitive advantage than the $C_{3}$ plant soybean (Table 1; Supplementary Figure S3). This can be explained by differences among these crop species. Soybean as legume plant can form tripartite symbiotic associations with rhizobia and AMF simultaneously (Wang et al., 2011). In the present study, rhizobial symbiosis stimulates the assimilation capacity of photosynthetic carbon in the $\mathrm{C}_{3}$ plant, soybean, which then invests more carbon into CMNs. Conversely, the $\mathrm{C}_{4}$ plant maize invests little carbon, yet receives $15 \%$ of its $\mathrm{N}$ from soybean through $\mathrm{N}$ transfer via CMNs.

Soybean is a weak competitor compared with maize in soybean/maize intercropping system. However, the overall productivity of the soybean/maize intercropping system is significantly higher than those of sole maize and soybean when co-inoculated with AMF and rhizobia under moderate nutrient supply conditions (Figure 1). Soybean and maize can be naturally inoculated by indigenous AM fungi and rhizobia in the field. Generally, indigenous rhizobia have low nodulation activities than those of inoculation (Qin et al., 2012). Therefore, effective rhizobium inoculation combined with indigenous AM fungi not only increases $\mathrm{N}$ uptake through symbiotic $\mathrm{N} 2$ fixation but also enhances $\mathrm{N}$ transfer by CMNs, which could subsequently contribute to improve intercropping advantages in soybean/maize intercropping system in the field.

\section{CONCLUSION}

These results showed that maize has a competitive advantage over soybean in soybean/maize intercropping system. The important aspect of this work is the demonstration that the growth advantage of maize is due to increased $\mathrm{N}$ acquisition from soybean via CMNs and a relatively low carbon investment into CMNs by maize growing with soybean under conditions favoring symbioses with both rhizobia and AMF.

\section{AUTHOR CONTRIBUTIONS}

XW and HL conceived the experiments. XW, JS, GW, LS, and DZ designed and performed the experiments. XW, JS and HL drafted the manuscript. XW and HL edited the manuscript. All authors approved the final version.

\section{FUNDING}

This research is supported by the "Strategic Priority Research Program" of the Chinese Academy of Sciences (XDB150302023 ), and the National Natural Science Foundation of China (31372126).

\section{ACKNOWLEDGMENTS}

We thank our colleague X. Lu for helpful discussions and comments, and Dr. T. Walk of Golden Fidelity LLC for corrections to the English.

\section{SUPPLEMENTARY MATERIAL}

The Supplementary Material for this article can be found online at: http://journal.frontiersin.org/article/10.3389/fpls.2016.01901/ full\#supplementary-material 


\section{REFERENCES}

Balzergue, C., Puech-Pages, V., Becard, G., and Rochange, S. F. (2011). The regulation of arbuscular mycorrhizal symbiosis by phosphate in pea involves early and systemic signalling events. J. Exp. Bot. 62, 1049-1060. doi: 10.1093/ jxb/erq335

Breuillin, F., Schramm, J., Hajirezaei, M., Ahkami, A., Favre, P., Druege, U., et al. (2010). Phosphate systemically inhibits development of arbuscular mycorrhiza in Petunia hybrida and represses genes involved in mycorrhizal functioning. Plant J. 64, 1002-1017. doi: 10.1111/j.1365-313X.2010.04385.x

Brooker, R. W., Bennett, A. E., Cong, W. F., Daniell, T. J., George, T. S., Hallett, P. D., et al. (2015). Improving intercropping: a synthesis of research in agronomy, plant physiology and ecology. New Phytol. 206, 107-117. doi: 10.1111/nph.13132

Deslippe, J. R., Hartmann, M., Grayston, S. J., Simard, S. W., and Mohn, W. W. (2016). Stable isotope probing implicates a species of Cortinarius in carbon transfer through ectomycorrhizal fungal mycelial networks in Arctic tundra. New Phytol. 210, 383-390. doi: 10.1111/nph.13797

Fan, F., Zhang, F., Song, Y., Sun, J., Bao, X., Guo, T., et al. (2006). Nitrogen fixation of faba bean (Vicia faba L.) interacting with a non-legume in two contrasting intercropping systems. Plant Soil 283, 275-286. doi: 10.1007/s11104-0060019-y

Fellbaum, C. R., Mensah, J. A., Cloos, A. J., Strahan, G. E., Pfeffer, P. E., Kiers, E. T., et al. (2014). Fungal nutrient allocation in common mycorrhizal networks is regulated by the carbon source strength of individual host plants. New Phytol. 203, 646-656. doi: 10.1111/nph.12827

Hauggaard-Nielsen, H., and Jensen, E. S. (2001). Evaluating pea and barley cultivars for complementarity in intercropping at different levels of soil nitrogen availability. Field Crops Res. 72, 185-196. doi: 10.1016/S0378-4290(01)00176-9

He, X., Critchley, C., Ng, H., and Bledsoe, C. (2004). Reciprocal N $\left({ }^{15} \mathrm{NH}_{4}^{+}\right.$or ${ }^{15} \mathrm{NO}_{3}^{-}$) transfer between nonN $\mathrm{N}_{2}$-fixing Eucalyptus maculata and $\mathrm{N}_{2}$-fixing Casuarina cunninghamiana linked by the ectomycorrhizal fungus Pisolithus sp. New Phytol. 163, 629-640. doi10.1111/j.1469-8137.2004.01137.x

He, X., Critchley, C., Ng, H., and Bledsoe, C. (2005). Nodulated N2-fixing Casuarina cunninghamiana is the sink for net $\mathrm{N}$ transfer from non-N2fixing Eucalyptus maculata via an ectomycorrhizal fungus Pisolithus sp. using $15 \mathrm{NH} 4+$ or 15NO3- supplied as ammonium nitrate. New Phytol. 167, 897-912. doi: 10.1111/j.1469-8137.2005.01437.x

He, X., Xu, M., Qiu, G. Y., and Zhou, J. (2009). Use of $15 \mathrm{~N}$ stable isotope to quantify nitrogen transfer between mycorrhizal plants. J. Plant Ecol. 2, 107-118. doi: $10.1093 /$ jpe/rtp015

Jamont, M., Piva, G., and Fustec, J. (2013). Sharing N resources in the early growth of rapeseed intercropped with faba bean: does N transfer matter? Plant Soil 371, 641-653. doi: 10.1007/s11104-013-1712-2

Johnson, D., Leake, J. R., Ostle, N., Ineson, P., and Read, D. J. (2002). In situ 13CO2 pulse labeling of upland grassland demonstrates a rapid pathway of carbon flux from arbuscular mycorrhizal mycelia to the soil. New Phytol. 153, 327-334. doi: 10.1046/j.0028-646X.2001.00316.x

Kaschuk, G., Kuyper, T. W., Leffelaar, P. A., Hungria, M., and Giller, K. E. (2009). Are the rates of photosynthesis stimulated by the carbon sink strength of rhizobial and arbuscular mycorrhizal symbioses? Soil Biol. Biochem. 41, 1233-1244. doi: 10.1016/j.soilbio.2009.03.005

Laberge, G., Haussmann, B., Ambus, P., and Høgh-Jensen, H. (2011). Cowpea $\mathrm{N}$ rhizodeposition and its below-ground transfer to a co-existing and to a subsequent millet crop on a sandy soil of the Sudano-Sahelian eco-zone. Plant Soil 340, 369-382. doi: 10.1007/s11104-010-0609-6

Ledgard, S. F., Freney, J. R., and Simpson, J. R. (1985). Assessing nitrogen transfer from legumes to associated grasses. Soil Biol. Biochem. 17, 575-577. doi: 10. 1016/0038-0717(85)90028-8

Li, B., Li, Y. Y., Wu, H. M., Zhang, F. F., Li, C. J., Li, X. X., et al. (2016). Root exudates drive interspecific facilitation by enhancing nodulation and N2 fixation. Proc. Nati. Acad. Sci. U.S.A. 23, 6496-6501. doi: 10.1073/pnas. 1523580113

Li, L., Li, S. M., Sun, J. H., Zhou, L. L., Bao, X. G., Zhang, H. G., et al. (2007). Diversity enhances agricultural productivity via rhizosphere phosphorus facilitation on phosphorus-deficient soils. Proc. Nati. Acad. Sci. U.S.A. 104, 11192-11196. doi: 10.1073/pnas.0704591104
Lu, Y., Watanabe, A., and Kimura, M. (2002a). Contribution of plant-derived carbon to soil microbial biomass dynamics in a paddy rice microcosm. Biol. Fert. Soils 36, 136-142. doi: 10.1007/s00374-002-0504-2

Lu, Y., Watanabe, A., and Kimura, M. (2002b). Input and distribution of photosynthesized carbon in a flooded rice soil. Global Biogeochem. Cy. 16, 1085-1093. doi: 10.1029/2002GB001864

Maffei, M., and Mucciarelli, M. (2003). Essential oil yield in peppermint/soybean strip intercropping. Field Crops Res. 84, 229-240. doi: 10.1016/S0378-4290(03) 00092-3

Meding, S. M., and Zasoski, R. J. (2008). Hyphal-mediated transfer of nitrate, arsenic, cesium, rubidium, and strontium between arbuscular mycorrhizal forbs and grasses from a California oak woodland. Soil Biol. Biochem. 40, 126-134. doi: 10.1016/j.soilbio.2007.07.019

Meng, L., Zhang, A., Wang, F., Han, X., Wang, D., and Li, S. (2015). Arbuscular mycorrhizal fungi and rhizobium facilitate nitrogen uptake and transfer in soybean/maize intercropping system. Front. Plant Sci. 6:339. doi: 10.3389/fpls. 2015.00339

Mikkelsen, B. L., Rosendahl, S., and Jakobsen, I. (2008). Underground resource allocation between individual networks of mycorrhizal fungi. New Phytol. 180, 890-898. doi: 10.1111/j.1469-8137.2008.02623.x

Newman, E. I., Devoy, A. L., Basen, N. J., and Fowles, K. J. (1994). Plant species that can be linked by VA mycorrhizal fungi. New Phytol. 126, 691-693. doi: 10.1111/j.1469-8137.1994.tb02963.x

Paynel, F., Lesuffleur, F., Bigot, J., Diquélou, S., and Cliquet, J. B. (2008). A study of $15 \mathrm{~N}$ transfer between legumes and grasses. Agron. Sustain. Dev. 28, 281-290. doi: 10.1051/agro:2007061

Qin, L., Zhao, J., Tian, J., Chen, L. Y., Sun, Z. A., Guo, Y. X., et al. (2012). The highaffinity phosphate transporter GmPT5 regulates phosphate transport to nodules and nodulation in soybean. Plant Physiol. 159, 1634-1643. doi: 10.1104/pp.112. 199786

Shen, Q., and Chu, G. (2004). Bi-directional nitrogen transfer in an intercropping system of peanut with rice cultivated in aerobic soil. Biol. Fert. Soils 40, 81-87. doi: 10.1007/s00374-004-0737-3

Sierra, J., and Nygren, P. (2006). Transfer of N fixed by a legume tree to the associated grass in a tropical silvopastoral system. Soil Biol. Biochem. 38, 1893-1903. doi: 10.1016/j.soilbio.2005.12.012

Simard, S. W., Beiler, K. J., Bingham, M. A., Deslippe, J. R., Philip, L. J., and Teste, F. P. (2012). Mycorrhizal networks: mechanisms, ecology and modelling. Fungal Biol. Rev. 26, 39-60. doi: 10.1016/j.fbr.2012.01.001

Tang, J. C., Mboreha, I. A., She, L. N., Liao, H., Chen, H. Z., Sun, Z. D., et al. (2005). Nutritional effects of soybean root architecture in a maize/soybean intercropping system. Sci. Agric. Sin. 38, 1196-1203.

Tisserant, E., Malbreil, M., Kuo, A., Kohler, A., Symeonidi, A., Balestrini, R., et al. (2013). Genome of an arbuscular mycorrhizal fungus provides insight into the oldest plant symbiosis. Proc. Natl. Acad. Sci. U.S.A. 110, 20117-20122. doi: 10.1073/pnas.1313452110

Walder, F., Niemann, H., Natarajan, M., Lehmann, M. F., Boller, T., and Wiemken, A. (2012). Mycorrhizal networks: common goods of plants shared under unequal terms of trade. Plant Physiol. 159, 789-797. doi: 10.1104/pp.112. 195727

Wang, X., Pan, Q., Chen, F., Yan, X., and Hong, L. (2011). Effects of co-inoculation with arbuscular mycorrhizal fungi and rhizobia on soybean growth as related to root architecture and availability of $\mathrm{N}$ and P. Mycorrhiza 21, 173-181. doi: 10.1007/s00572-010-0319-1

Wang, X., Zhao, S., and Bücking, H. (2016). Arbuscular mycorrhizal growth responses are fungal specific but do not differ between soybean genotypes with different phosphate efficiency. Ann. Bot. 118, 11-21. doi: 10.1093/aob/ mcw074

Willey, R. W., and Rao, M. R. (1980). A competitive ratio for quantifying competition between intercrops. Exp. Agric. 16, 117-125. doi: 10.1017/ S0014479700010802

Wright, D. P., Read, D. J., and Scholes, J. D. (1998). Mycorrhizal sink strength influences whole plant carbon balance of Trifolium repens L. Plant Cell Environ. 21, 881-891. doi: 10.1046/j.1365-3040.1998. 00351.x

Xiao, Y., Li, L., and Zhang, F. (2004). Effect of root contact on interspecific competition and $\mathrm{N}$ transfer between wheat and fababean using direct 
and indirect $15 \mathrm{~N}$ techniques. Plant Soil 262, 45-54. doi: 10.1023/B:PLSO. $0000037019.34719 .0 \mathrm{~d}$

Xue, Y., Xia, H., Christie, P., Zhang, Z., Li, L., and Tang, C. (2016). Crop acquisition of phosphorus, iron and zinc from soil in cereal/legume intercropping systems: a critical review. Ann. Bot. 117, 363-377. doi: 10.1093/aob/ mcv182

Zhang, S., Zhou, J., Wang, G. H., Wang, X. R., and Liao, H. (2015). The role of mycorrhizal symbiosis in aluminum and phosphorus interactions in relation to aluminum tolerance in soybean. Appl. Microbiol. Biot. 99, 10225-10235. doi: 10.1007/s00253-015-6913-6
Conflict of Interest Statement: The authors declare that the research was conducted in the absence of any commercial or financial relationships that could be construed as a potential conflict of interest.

Copyright $\odot 2016$ Wang, Sheng, Zhao, Sheng, Wang and Liao. This is an open-access article distributed under the terms of the Creative Commons Attribution License (CC BY). The use, distribution or reproduction in other forums is permitted, provided the original author(s) or licensor are credited and that the original publication in this journal is cited, in accordance with accepted academic practice. No use, distribution or reproduction is permitted which does not comply with these terms. 